\title{
Avaliando a política de saúde mental num CAPS: a trajetória no movimento antimanicomial
}

\section{Evaluating the politics of mental health in a CAPS: the path in the anti-asylum movement}

\section{Luciane Prado Kantorski*}

Professora da Faculdade de Enfermagem e Obstetrícia da Universidade Federal de Pelotas, Pelotas, RS, Brasil

\section{Vanda Maria da Rosa J ardim**}

Professora da Faculdade de Enfermagem e Obstetrícia da Universidade Federal de Pelotas, Pelotas, RS, Brasil

\section{Valéria Cristina Christello Coimbra***}

Professora da Faculdade de Enfermagem e Obstetrícia da Universidade Federal de Pelotas, Pelotas, RS, Brasil

\section{Álvaro Moreira Hypólito****}

Professor Associado da Faculdade de Educação da Universidade Federal de Pelotas, Pelotas, RS, Brasil

\section{Ariane da Cruz Guedes}

Mestranda do Programa de Pós-Graduação em Enfermagem da Universidade Federal de Pelotas, Pelotas, RS, Brasil

\section{Maria Carolina Meirelles}

Mestranda do Programa de Pós-Graduação em Enfermagem da Universidade Federal de Pelotas, Pelotas, RS, Brasil

\section{Bianca Neme Clasen $* * * * * * *$}

Mestranda do Programa de Pós-Graduação em Enfermagem da Universidade Federal de Pelotas, Pelotas, RS, Brasil

\section{Cláudio Tosi Cavada********}

Mestrando do Programa de Pós-Graduação em Enfermagem da Universidade Federal de Pelotas, Pelotas, RS, Brasil

\section{J andro Moraes Cortes}

Acadêmico da Faculdade de Enfermagem e Obstetrícia da Universidade Federal de Pelotas, Pelotas, RS, Brasil 


\section{RESUMO}

Este artigo aborda um estudo de caso do Centro de Atenção Psicossocial (CAPS) de Alegrete - Rio Grande do Sul/Brasil e consiste num recorte do estudo de avaliação dos CAPS do sul do Brasil $^{1}$, em cuja etapa qualitativa foram estudados cinco CAPS desta região. Tem como objetivo avaliar qualitativamente um CAPS tendo como marcador a política de saúde mental, enfatizando a relação do CAPS com a gestão local e com o movimento antimanicomial. Realizou-se uma avaliação de quarta geração, utilizando-se entrevistas com usuários, familiares e trabalhadores do CAPS e observação de campo. Foi evidenciado no processo avaliativo o potencial de organização e comprometimento dos sujeitos sociais na construção cotidiana do processo de transformação das práticas em saúde mental, apesar dos limites enfrentados no interior da política local.

Palavras-Chave: Centro de atenção psicossocial, Avaliação qualitativa de serviços, Política de saúde mental.

\section{ABSTRACT}

This article describes a study of case of a Center for Psychosocial Attendance (CAPS) located in Alegrete, Rio Grande do Sul, Brazil and it consists of a cutting of the study of evaluation of CAPS from the southern of Brazil, where, in the qualitative stage were studied five CAPS of this area. The aim of this study was to evaluate qualitatively a CAPS, using as marker the politics of mental health emphasizing the relationship of the CAPS with the local administration and with the anti-asylum movement. It was made a fourth generation evaluation, consisting of interviews with users, family members and workers of the CAPS and field observation. It was evidenced in the evaluating process the organization and compromising potentials of the social subjects in the daily construction of the process of transformation of the practices in mental health, in spite of the limits faced inside the local politics.

Keywords: Center for psychosocial attendance, Qualitative ASSESSMENT OF SERVICES, Mental health politics. 


\section{I ntrodução}

O presente artigo consiste no relato de um estudo de caso do Centro de Atenção Psicossocial (CAPS) de Alegrete - RS, constituindo-se num recorte da pesquisa de avaliação dos CAPS da região sul do Brasil, conhecida como CAPSUL. Esta se propôs a avaliar estrutura, processo de trabalho e resultados dos CAPS, ouvindo usuários, familiares, trabalhadores e coordenadores dos serviços nos três estados, através de uma investigação que se desdobra em um estudo qualitativo e um estudo quantitativo.

No Estudo de Avaliação Quantitativa de CAPS optou-se pela abordagem epidemiológica que avaliou a estrutura, o processo e o resultado (DONABEDIAN, 1984; 1988) da atenção em saúde mental desenvolvida pelos CAPS da região sul do Brasil. De um total de 102 CAPS (52 CAPS I e 50 CAPS II, nos três estados da Região Sul do Brasil), registrados no Ministério da Saúde no ano de 2005, foram sorteados aleatoriamente a partir de uma amostra que respeitou a proporcionalidade de serviços por estado: 3 CAPS no Paraná; 9 CAPS em Santa Catarina e 18 CAPS no Rio Grande do Sul.

O Estudo de Avaliação Qualitativa de CAPS realizou-se a partir da fundamentação teórico-metodológica da avaliação construtivista, responsiva e com abordagem hermenêutico-dialética. A Avaliação de Quarta Geração, desenvolvida por Egon G. Guba e Yvona S Lincoln, foi norteadora do processo teórico-metodológico da pesquisa e os instrumentos de coleta de dados foram entrevistas com equipe, usuários e familiares (definidos como grupos de interesse para compor o círculo hermenêutico-dialético) e observação de campo. A etapa qualitativa do estudo concentrou-se em Centros de Atenção Psicossocial I e II, de cinco municípios da região sul do país, desenvolvida na forma de estudo de caso (GUBA; LINCOLN, 1989).

Os CAPS são serviços substitutivos implementados a partir da transformação da assistência psiquiátrica no Brasil e constituem-se como serviços estratégicos para a implementação da reforma psiquiátrica. O novo enfoque não busca meramente modernizar as tecnologias de atenção psiquiátrica e difundi-las, mas busca "redescrever, reconstruir as relações entre a sociedade e seus loucos. Não se trata de secundarizar a questão técnica, assistencial, mas de redefinir seu lugar numa estratégia mais ampla de ação" (BEZERRA JÙNIOR, 1994, p.181).

A expansão do atendimento a saúde mental em serviços substitutivos em diversos municípios do país indica que, como política pública de atenção em saúde mental, os CAPS têm sido percebidos como tendo potencial para responder, de forma efetiva, às questões locais, configurando-se como um dos equipamentos centrais na implantação do Sistema Local de Saúde Mental. 
No caso da saúde mental, a mudança do enfoque exige a implantação de uma diversidade de equipamentos que respondam aos diferentes momentos e necessidades da pessoa. Nessa direção, um processo avaliativo dos CAPS deve levar em conta que os mesmos, de forma isolada e fora de uma estrutura de rede, podem dar respostas parciais não apenas devido às suas limitações intrínsecas, mas também por não estarem inseridos em uma proposta política mais ampla.

O presente estudo justifica-se, principalmente, pela premência de se avaliar essas novas modalidades públicas de atenção em saúde mental e tem como objetivo avaliar qualitativamente um CAPS tendo como marcador a política de saúde mental num município enfatizando a relação do CAPS com a gestão local e com o movimento antimanicomial.

\section{Percurso Metodológico}

Trata-se de uma pesquisa do tipo estudo de caso. Os estudos de caso apresentam características importantes tais como: visam à descoberta, enfatizam a interpretação em contexto, buscam retratar a realidade de forma completa e profunda, usam uma variedade de fontes de informação, revelam experiências de vida e permitem generalizações naturalísticas, procuram representar os diferentes e às vezes conflitantes pontos de vista presente numa situação social e utilizam uma linguagem e uma forma mais acessível do que os outros relatórios de pesquisa (LÜDKE; ANDRÉ, 1986).

Segundo Yin (2005) o estudo de caso é uma investigação empírica que aborda um fenômeno contemporâneo dentro de seu contexto de vida real, especialmente quando os limites entre o fenômeno e o contexto não estão definidos. A investigação através do estudo de caso visa apreender uma situação tecnicamente única baseando-se em várias fontes de evidência, com os dados convergindo num triângulo e beneficiando-se do desenvolvimento prévio de proposições teóricas, que visam conduzir a coleta e análise dos dados. O autor ressalta a importância dos estudos de caso na pesquisa avaliativa evidenciando sua potencialidade em descrever o contexto real em que se dá a intervenção e a sua capacidade em explorar situações específicas, o que não seria possível somente pela análise dos resultados, por identificar na realidade estudada inter-relações entre pressupostos e práticas concretas de serviços e programas.

A etapa qualitativa do estudo de avaliação CAPSUL concentrou-se em Centros de Atenção Psicossocial I e II, de cinco municípios da região sul do país, no período de julho a dezembro de 2006, e desenvolvida na forma de estudo de caso por acreditar-se que este tipo de estudo adequava-se a necessidade de reconhecer especificamente aspectos da constituição da trajetória destes CAPS que se mostravam 
singulares nas formas de cuidar do sofrimento psíquico no território. Deste modo, em uma escolha intencional, foram selecionados cinco CAPS, tendo como parâmetro os dados obtidos na etapa de avaliação epidemiológica quantitativa de 30 CAPS da região sul do Brasil, referentes à estrutura, processo e sua adequação às normas definidas pela Portaria no 336/2002. Foram também considerados 0 tempo de funcionamento e experiência dos serviços e a disponibilidade dos grupos de interesse em aderirem à proposta da avaliação qualitativa.

O presente artigo dedica-se a analisar especificamente aspectos que emergiram na avaliação qualitativa realizada nos grupos de interesse dos usuários, familiares e trabalhadores do CAPS, sobre a política de saúde mental enfatizando a relação do CAPS com a gestão local e com o movimento antimanicomial, a partir dos dados obtidos no CAPS II de Alegrete - RS, um dos estudos de caso que integrou a pesquisa CAPSUL. Os instrumentos de coleta de dados foram entrevistas semi-estruturadas com equipe (26), usuários (11) e familiares (14) e a observação de campo (390 horas).

O Estudo de Avaliação Qualitativa de Centros de Atenção Psicossocial da região sul do Brasil utilizou-se da avaliação de quarta geração construtivista, responsiva e com abordagem hermenêutico-dialética desenvolvida por Guba e Lincoln $(1985 ; 1989 ; 1998)$ e adaptada por Wetzel (2005).

A avaliação de Quarta Geração é uma forma de avaliação em que as questões dos stakeholders (grupos de interesse) servem como foco organizacional (a base para determinar que informação é necessária), e é implementada através dos pressupostos metodológicos do paradigma construtivista (GUBA; LINCOLN, 1989).

Guba; Lincoln (1989) propõe, como alternativa às avaliações tradicionais, uma avaliação responsiva, baseada em um referencial construtivista. O termo responsiva é usado para designar uma diferente forma de focalizar uma avaliação em relação aos seus parâmetros e limites: nos modelos tradicionais os parâmetros e limites são definidos a priori. A avaliação responsiva determina parâmetros e limites através de um processo interativo e de negociação que envolve grupos de interesse. O termo construtivista é usado para designar a metodologia empregada para realizar a avaliação.

O processo de qualquer avaliação deve começar com um método para determinar quais questões serão colocadas e quais informações serão buscadas. Os elementos a serem enfocados: variáveis, objetivos, decisões e outros, podem ser denominados de organizadores de avanço (advance organizers). A avaliação responsiva também tem seus organizadores de avanço: 'as reivindicações, preocupações e questões que serão identificadas por grupos de interesse 
(stakeholders), isto é, pessoas que serão potencialmente vítimas ou beneficiários da avaliação (GUBA; LINCOLN, 1989).

Guba e Lincoln (1989) propõe o processo hermenêutico-dialético como um caminho para alcançar as condições anteriormente expostas. É hermenêutico porque tem caráter interpretativo, e dialético porque implica em comparação e contraste de diferentes pontos de vista, objetivando um alto nível de síntese.

A presente avaliação pretendeu apreender a dinâmica do serviço, a forma como os atores interagiam e os sentidos construídos pelos mesmos em relação com sua prática. Junto com isso, manteve-se a preocupação em realizar uma avaliação que pudesse ser também dispositivo, possibilitando que os grupos de interesse ampliassem sua capacidade de intervirem sobre a realidade do serviço.

A avaliação qualitativa de quarta geração com a utilização do círculo hermenêutico-dialético foi o referencial teórico e metodológico escolhido para o presente estudo por se tratar de uma avaliação participativa que possibilita dar voz ao usuário do serviço, ao seu familiar e a equipe do CAPS. Consideramos que o processo de transformação da atenção em saúde mental preconiza o fortalecimento do poder de contratualidade e empoderamento dos usuários e necessita de metodologias de pesquisa coerentes com esta demanda. Consiste num processo de avaliação formativa e responsiva possibilitando que as oficinas de validação dos dados constituam-se em momentos de reflexão e negociação sobre as questões mais críticas em relação ao modo de atenção psicossocial e sobre as mudanças necessárias para promover avanços no serviço avaliado.

A aplicação prática da Avaliação Qualitativa de Quarta Geração aconteceu por meio de:

1. Contato com o campo e organização da avaliação: contato com a equipe do serviço, sendo apresentada e discutida a proposta da pesquisa. Após esta etapa realizou-se o período de observação em que a principal tarefa foi ganhar o direito de entrada, o que envolveu, principalmente, a construção de uma relação de confiança com as pessoas. Em uma avaliação em que se pretendeu que os interessados falassem sobre seus problemas. Outro aspecto fundamental nessa fase foi o período de observação de campo que propiciou aos avaliadores a vivência e experiência do contexto do serviço, conversando com as pessoas, identificando os líderes informais, sem ainda estar engajado nas atividades de avaliação, o que Guba e Lincoln (1989) denominam de etnografia prévia (prior ethnography).

A avaliação qualitativa fornece descrições detalhadas das atividades, dos processos e dos participantes do programa, sendo a observação direta um importante recurso (PATTON, 1987).

Lincoln e Guba (1985) colocam que, a observação pode tomar diferentes formas nos diferentes estágios da pesquisa. Na fase inicial, 
a observação pode ser pouco estruturada, de forma a permitir que o observador expanda o seu conhecimento e desenvolva algum senso do que é importante. Mais tarde, o observador pode torná-la mais focal, aprofundando aspectos necessários a investigação.

2. Identificação dos stakeholders ou grupos de interesse: esses grupos são formados por pessoas com características comuns que têm algum interesse no desempenho, no produto ou no impacto do objeto da avaliação. Foram incluídos na pesquisa três grupos de interesse: equipe, usuários e familiares.

Os sujeitos que compuseram cada grupo de interesse foram definidos intencionalmente a partir dos seguintes critérios:

- Equipe: foram incluídos todos os trabalhadores que possuíam vínculo empregatício com o serviço (enfermeiro, assistente social, psicólogo, professor de educação física, técnico de enfermagem, pessoal da recepção, da portaria, pessoal da limpeza, dentre outros).

- Usuários: foram incluídos usuários que freqüentavam o serviço a mais de três meses; que tinham boas condições de comunicação; usuários com bom vínculo com o serviço e também usuários com vínculo ruim ou prejudicado.

- Familiares: foram incluídos os familiares com pouca e com boa inserção no serviço, familiares de usuários com boa ou pouca adesão ao serviço; também familiares considerados "difíceis" pela equipe, aqueles que "não colaboram".

3. Desenvolvimento e ampliação das construções conjuntas: a aplicação do círculo hermenêutico-dialético.

Essa fase envolveu a aplicação do círculo hermenêutico-dialético (Figura 1) nos três grupos de interesse selecionados. Iniciou-se com a seleção de um respondente inicial (R1), sendo realizada uma entrevista aberta para determinar uma construção inicial em relação ao foco da avaliação. Pediu-se que o respondente descrevesse e avaliasse 0 atendimento do CAPS e o comentasse em termos pessoais, incluindo observações sobre os aspectos positivos e negativos do serviço. Os temas centrais, conceitos, idéias, valores, problemas e questões propostas por R1 foram analisados pelos pesquisadores, em uma formulação inicial da sua construção, designada C1. Desse modo, a análise dos dados ocorreu concomitante à coleta. Após, um segundo respondente (R2) foi entrevistado. Quando R2 colocou todas as questões relacionadas a pergunta inicial, os temas oriundos da análise da entrevista de R1 foram introduzidos, e R2 foi convidado a comentá-los. Como resultado, a entrevista com R2 produziu informações não apenas sobre R2, mas também críticas às demandas e construções de R1. O pesquisador completou a segunda análise (C2), surgindo construções mais bem informadas e sofisticadas baseadas em duas fontes. $O$ processo foi repetido através da adição de novos informantes, sendo 
entrevistados todos os componentes de determinado grupo de interesse.

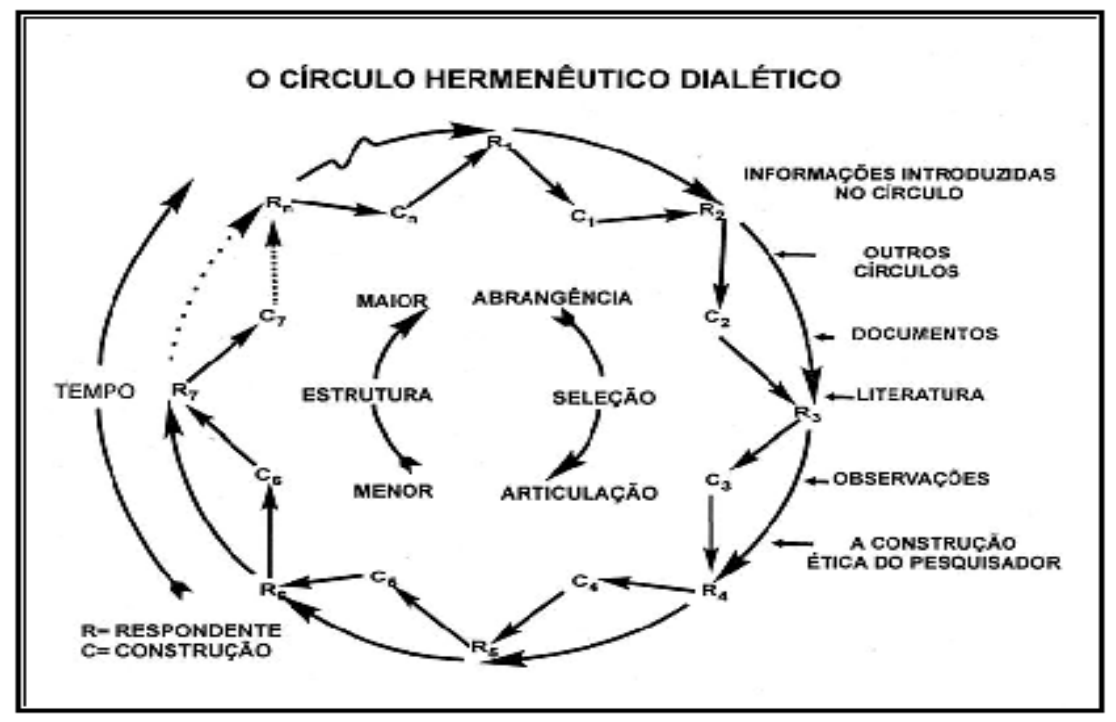

Figura 1 - Círculo Hermenêutico Dialético.

Fonte: Traduzido por Wetzel (2005) a partir de Guba ; Lincoln (1989)

É muito comum que diferentes atores tenham diferentes construções a respeito de reivindicações, preocupações e questões particulares. A maior tarefa do avaliador consiste em conduzir a avaliação de forma que cada grupo confronte as suas construções com as demais, um processo que denominamos hermenêutico-dialético (GUBA; LINCOLN, 1989).

4. Apresentação das questões para os grupos de interesse: consistiu na organização das construções do grupo, para que pudessem ter a oportunidade de validá-las, ou seja, modificá-las ou afirmar a sua credibilidade.

Após a coleta dos dados brutos da entrevista, foi realizada uma análise prévia com o objetivo de estruturar as oficinas de validação das informações obtidas dos diferentes grupos de interesses envolvidos. Então os dados refinados foram apresentados para os respectivos grupos, para que tivessem acesso à totalidade das informações e a oportunidade de modificá-las ou afirmar a sua credibilidade. A negociação foi realizada mediante a utilização da técnica grupal, sendo convidados todos os entrevistados de determinado círculo (usuários, familiares e equipe).

Os marcadores da avaliação qualitativa emergiram enquanto questões e parâmetros de avaliação, resultantes da síntese dos dados coletados no trabalho de campo. As análises seguiram uma orientação teórica já utilizada na etapa da avaliação quantitativa da pesquisa CAPSUL, enfocando a estrutura, o processo e os resultados da atenção psicossocial no CAPS (DONABEDIAN, 1984; 1988). Por marcadores denominou-se determinada categoria que foi abstraída a 
partir dos dados empíricos e que tem a capacidade explicativa de indicar determinado parâmetro de avaliação.

A partir da orientação teórica da avaliação de quarta geração, os parâmetros de avaliação, neste estudo denominados de marcadores, foram definidos pelos grupos de interesse, pois são estes que podem elencar prioridades a serem discutidas e as transformações necessárias para qualificar os serviços a partir da avaliação. Assim um dos marcadores da avaliação qualitativa do CAPS de Alegrete - RS consistiu na política de saúde mental considerando as contradições que permeiam o caso de Alegrete-RS, tendo em vista a consolidação de conquistas do movimento antimanicomial no município e a incipiente compreensão da gestão local da dimensão da proposta de atenção em saúde mental implementada.

O projeto de pesquisa de Avaliação dos CAPS da região sul do Brasil (CAPSUL) foi apreciada e aprovada pelo Comitê de Ética e Pesquisa da Faculdade de Medicina da Universidade Federal de Pelotas (Of. 074/05 de 11 de novembro de 2005). Todos os entrevistados concordaram em participar da pesquisa mediante a assinatura de consentimento livre e esclarecido. No texto as observações de campo são identificadas pela letra "o" seguida da numeração correspondente ao observador, com relação aos entrevistados os usuários são identificados pela letra " $U$ ", os familiares pela letra " $F$ " e a equipe pela letra " $\mathrm{E}$ ", seguida do número correspondente à entrevista.

\section{O movimento antimanicomial no contexto de Alegrete}

O movimento antimanicomial tem uma dimensão política, pois organiza sua luta em torno de um projeto comum que é a consolidação de um modo de cuidar do sofrimento psíquico com suas bases comunitárias, focado na inserção social e na transformação das relações da sociedade com a loucura. Essa transformação passa pelo engajamento de cada sujeito da saúde mental seja ele trabalhador, familiar, usuário, amigo, enfim institui mecanismos de solidariedade que dão corpo à luta e permitem que através da palavra seja dada expressão à "voz do louco".

O movimento da luta antimanicomial em sua dimensão política constitui-se como um importante movimento social na sociedade brasileira, pois suas ações e lutas vêm tendo impacto nas diferentes dimensões da vida social contribuindo para a transformação da relação da sociedade com o louco e a loucura. (LÜCHMANN; RODRIGUES, 2007)

A política, neste caso consiste num artifício da razão e se configura numa espécie de encontro com o diferente num mundo de interesses desiguais. O posicionamento do sujeito no mundo se dá através da apropriação da palavra, que fundará o mundo humanizado, através 
do conflito, da discussão, do dissenso e da participação (ARENDT, 1987).

A reforma psiquiátrica possibilita que a palavra seja expressa e que essa expressão possa ser viabilizada nos espaços públicos de gestão, na associação, no CAPS, na comunidade. Os sujeitos sociais envolvem-se em embates e conflitos numa arena que é política sim, no sentido mais genuíno da palavra disputando sistematicamente com diferentes atores através da apropriação da palavra a consolidação da reforma psiquiátrica. Se por um lado isto pode parecer um processo desgastante, por outro em Alegrete tem representado a consolidação do modo psicossocial e a constituição de sujeitos da saúde mental visceralmente comprometidos com a proposta de mudança.

Um aspecto importante das Políticas Públicas e da gestão consiste na forma como foi se estruturando as relações do CAPS no interior da luta antimanicomial e no interior das políticas públicas do município. As formas de organização do serviço, a importância de conversar com a comunidade e a qualificação da equipe.

\begin{abstract}
Nós, o serviço, desde o início. Acho que é uma das coisas que nos ajuda hoje a estar no padrão que a gente está, porque desde o início a gente começou trabalhando com uma proposta de planejamento e já o enfoque voltado para questão da saúde mental coletiva, da reforma psiquiátrica e da luta antimanicomial [...] É a importância da conversa com o povo Alegretense e, a gente usava muito a estratégia de rádio, de informativo, de mobilização na rua, no calçadão, na praça, fazendo projeto de interferência com a comunidade. Tudo que era data era motivo para estar na rua. Não só no dia da luta antimanicomial. Era no dia mundial da saúde. Sempre tinha um dia, e a gente sempre estava em todos os movimentos que podiam fazer a inserção, fazendo panfleto, indo na rádio sempre, nos jornais, indo, em tudo que era lugar que nos chamavam. [E 4].
\end{abstract}

De acordo com Kantorski e Silva (2001), a reforma psiquiátrica implica na extinção do manicômio, na transformação da rede de assistência psiquiátrica, em modificações legislativas e administrativas e, sobretudo, na transformação das relações da sociedade com o diferente, respeitando seu direito á palavra, viabilizando a expressão da voz e a escuta e construindo outros saberes e práticas acerca do sofrimento psíquico.

A Reforma implica em transformar saberes e práticas em relação à loucura, perceber a complexidade do objeto, recompreender o sofrimento psíquico, e efetivamente destruir manicômios externos e internos que têm permitido a constituição de determinadas formas de pensar e agir e, 
fundamentalmente, re-inventar modos de se lidar com a realidade. (KANTORSKI; SILVA, 2001, p. 142)

Conforme as autoras, a consolidação de um novo modelo de atenção em saúde mental, e mais, a transformação da relação da sociedade com a loucura se encontra permeada por disputas de poder e divergência de interesses, ressaltando-se a importância dos serviços substitutivos realizarem um trabalho educativo com vistas à desmistificação da loucura e, sobretudo, que tal trabalho esteja articulado às mobilizações populares que pretendem construir um mundo que acolha.

O principal desafio da reforma psiquiátrica consiste em promover rupturas e radicalização, e não promover pactos entre 0 aparentemente novo e aquilo que representa a manutenção de séculos de dominação (ALVERGA; DIMENSTEIN, 2006).

O Movimento da Luta Antimanicomial tem mantido esta característica de um movimento social que articula suas demandas em espaços públicos dos quais compartilham outras organizações sociais como associações, sindicatos, conselhos profissionais, organizações de familiares, usuários e trabalhadores de saúde mental.

Fernandes (2001) destaca que, este movimento social desde sua formação reivindica o alcance da cidadania aos indivíduos portadores de sofrimento psíquico, trazendo para a esfera pública questões sociais relevantes e trazendo a cena indivíduos e coletividades, eventualmente dela excluídos. Neste espaço da esfera pública o movimento pode combater e defender-se de uma cultura manicomial majoritária e defender seus interesses através do convencimento de outros públicos do caráter justo de suas reivindicações.

Particularmente no estado do Rio Grande do Sul, em que se insere o CAPS de Alegrete, do ponto de vista histórico o movimento da luta antimanicomial ganha corpo na década de 80. Oliveira e Saldanha (1993), ao elaborarem um relato reflexivo acerca da trajetória da saúde mental coletiva no Rio Grande do Sul, destacam que após 1986, com a eleição de um governador oriundo de forças que se opuseram à ditadura é aberto um espaço na Secretaria Estadual de Saúde que possibilitava a discussão e introdução de propostas inovadoras no campo da saúde mental.

No processo de mudança um dos primeiros passos consistiu na elaboração de um diagnóstico da situação, onde foi identificada a necessidade de capacitação das pessoas, sendo já de início promovidas algumas mudanças na residência interdisciplinar em saúde mental do Hospital Psiquiátrico São Pedro (estas em uma relação conjunta entre hospital e Escola de Saúde Pública). A seguir, foram organizados pré-encontros que antecederam a $1^{\text {a }}$ Conferência Nacional de Saúde Mental e eleitos os delegados para participar na conferência, entre estes três usuários, sendo o RS a única delegação 
nesta oportunidade a contar com representação dos usuários (OLIVEIRA; SALDANHA, 1993).

Teve papel importante neste processo quando em junho de 1987, começam os intercâmbios com a Argentina e o Uruguai, estendendose depois para países como Paraguai, Cuba, Espanha, Itália entre outros. Do primeiro intercâmbio com a Argentina originou-se um documento intitulado Delineamentos da Política de Saúde Mental para - Rio Grande do Sul (como resultado de um curso de aperfeiçoamento concluído em outubro de 1987). A saúde mental passa então a ser assumida, inserida nas demais políticas sociais, e compreendidos seus encaminhamentos estratégicos sob o referencial do pensamento estratégico. Este referencial adotado entende política como estratégias de distribuição de poder e este poder é pensado no cotidiano em seu conteúdo societário, assumindo a seguinte conformação: poder técnico, poder administrativo e poder político (TESTA, 1992).

Os intercâmbios seguiram-se por 1988 e constituiu-se nestas articulações o Foro Concórdia de Salud Mental e após a realização de dois Simpósios Internacionais de Saúde Mental em Santa Maria/RS, constituiu-se o Foro Uruguaio de Salud Mental. A capacitação de pessoas para o trabalho em saúde mental foi tomada como eixo principal do então Programa de Atenção Integral à Saúde Mental sendo realizados cursos de administração em saúde mental coletiva (de extensão e aperfeiçoamento) que abrangeram 150 municípios gaúchos, alguns municípios de Santa Catarina, Paraná e Uruguai e que capacitaram cerca de 450 pessoas. No transcurso, uma série de outros encontros foram realizados, sendo que em 1991 formou-se, a partir de uma avaliação das experiências realizadas, o Fórum Gaúcho de Saúde Mental(SAÚDE MENTAL COLETIVA, 1993). Ocorre que na segunda metade dos anos 80, tinham sido criados em torno de cinqüenta serviços comunitários de saúde mental no RS. Estes serviços procuravam articular equipes com diferentes trabalhadores de saúde, viabilizando serviços conforme a necessidade da população e sob os princípios da municipalização (OLIVEIRA; SALDANHA, 1993). O Fórum Gaúcho de Saúde Mental organizou-se no Rio Grande do Sul em 1991 e promoveu a "articulação de alianças, intercâmbios culturais, produção de pensamento, encontros afetivos, processo autogestivo" ( $\mathrm{p}$. 82). Tornou-se o ator principal na articulação de conferências municipais em saúde mental, era integrado por núcleos regionais e municipais e possuía como órgão de divulgação a revista Saúde Mental Coletiva, de publicação semestral, que veiculava produções que refletiam o pensar e o fazer em saúde mental com vistas à reforma psiquiátrica (SAÚDE MENTAL COLETIVA, 1993).

No interior deste debate sobre o CAPS enquanto serviço estratégico para implantação da reforma psiquiátrica as manifestações reforçam 
a importância do financiamento na consolidação deste processo e falam sobre a necessidade do serviço não se "encapsular". A equipe refere que o CAPS é apenas uma modalidade de serviço dentro de uma proposta de atenção integral a saúde mental.

Durante o trabalho de campo percebemos que há um questionamento permanente, no fazer do dia a dia, nas reuniões de equipe, nas conversas antes e pós-atendimentos, na proposição de atividades na comunidade, sobre a necessidade de problematizar posturas, do CAPS não se fechar em si mesmo, de manter a perspectiva da atenção integral enquanto modo de atenção psicossocial.

\begin{abstract}
Acho que o CAPS, ele foi importante para financiar, mas às vezes eu acho que ele atrapalhou o nosso modo de produção e organização do trabalho aqui dentro. A gente não tinha tanta coisa, tanta caixinha [...] Tem os intensivos, não intensivos, semi-intensivos [...] Não era assim. Todo o cuidado era intensivo. Não importava o tempo que ele vinha aqui" [E 6].

A gente chamava na época de Serviço de Atenção Integral à Saúde Mental. Isso é uma das coisas que a gente sempre luta para não perder, para não virar apenas um CAPS. A gente diz que o serviço é muito mais que um CAPS. O CAPS é uma modalidade que tem dentro do SAIS mental. Hoje tem a portaria em que está tudo bem especificado, o que é um CAPS, como é que se atende. E a preocupação sempre foi que o financiamento não fosse engessar o serviço. Que o serviço fosse para além do CAPS. Um CAPS é uma modalidade em função do financiamento. Mas a história dessa comunidade e o perfil com que esse serviço nasceu, era para além de um CAPS. Então, a gente até brincava, dizendo cuidado para gente não se encapsular. [E 5]
\end{abstract}

Para Campos (1992), o modelo assistencial consiste num conceito que estabelece intermediações entre o técnico e o político e configura-se em uma "síntese cambiante" que requer a concretização de diretrizes políticas e de princípios éticos, jurídicos, organizativos, clínicos, sócio-culturais, epidemiológicos e o desejo de viver saudável. Destaca que, além dos limites financeiros, o Brasil convive com o enfoque abusivamente normalizador das disciplinas em saúde mental e com uma transposição mecânica de diretrizes ordenadoras dos sistemas públicos de saúde - como é o caso da hierarquização e da regionalização. Alerta que a hierarquia dos serviços pode determinar a fragmentação da doença, impor rigidez de papéis e uma lógica definida por interesses corporativos ou burocráticos. O autor ressalta que, para assegurar a qualidade do cuidado e a legitimação dos serviços públicos pelos usuários, deve-se ter presente às noções de vínculo, acolhida, responsabilização pelo cuidado integral, que sobredeterminem o desenho do modelo assistencial. 
O engajamento da equipe nessa inversão de modelo assistencial é fundamental para que haja sucesso na construção de novas relações entre o CAPS, a comunidade, os recursos do território e o usuário que busca também significação para o seu sofrimento e um atendimento comprometido na resolução dos seus problemas de saúde em uma dimensão mais ampla (SILVEIRA; VIEIRA, 2005).

Lancetti (2001) nos fala da necessidade de consolidação de uma "clínica peripatética", entendida como a clínica praticada fora dos habituais settings (espaços situações e cenários em que se efetivam as técnicas terapêuticas) na abordagem de problemas que não têm obtido resposta nos protocolos tradicionais, ou seja, uma clínica praticada em movimento, fora dos espaços convencionais, viabilizando novas conexões e práticas. Segundo Lancetti (2001) este consiste no cerne da clínica antimanicomial, pois visa primordialmente, a interação do usuário com a cidade e as pessoas através de movimentos diversos no âmbito externo ao serviço de saúde.

Percebemos que a preocupação constante no trabalho de Alegrete em não se "encapsular", provoca sucessivos tensionamentos no sentido de promover a abertura do serviço. Em vários momentos no trabalho de campo foi verbalizada a necessidade dos trabalhadores de constituir uma organização interna do trabalho que viabilize mais as interações fora do serviço. Observamos ainda iniciativas, além daquelas de articulação no interior da rede de saúde, como o Projeto Rodas do Saber, a participação em eventos, os passeios, festas e viagens, a própria exposição de quadros realizada no Banco do Estado do Rio Grande do Sul, observadas durante o trabalho de campo que consistem em movimentos para além do serviço materializando investimentos de inserção no contexto mais geral da sociedade.

\section{O município de Alegrete e o CAPS}

O município de Alegrete localiza-se na fronteira oeste do Rio Grande do Sul a $506 \mathrm{Km}$ de distância da capital, Porto Alegre. Possui um total de 89.144 habitantes, sendo que destes 44.828 são do sexo feminino e 44.316 pertencem ao sexo masculino. A base da economia está centrada na agricultura e pecuária (BRASIL, 2007).

O serviço de saúde mental de Alegrete (CAPS) tem início em 1989, nessa época havia falta de recursos e as pessoas que trabalhavam na saúde mental eram designadas para esta área por motivo de punição e ou por que não tinham um bom desempenho em outros lugares. Com o passar do tempo o serviço foi se estruturando e ampliando seus espaços na sociedade. O CAPS é gerador de outros serviços substitutivos na rede de saúde mental, como: CAPS ad, CAPS i, residência terapêutica, articulações com os serviços de fonoaudiologia 
e fisioterapia. Vale ressaltar, que no início da estruturação do serviço havia uma preocupação da equipe em atender os usuários de baixa condição sócio-econômica, mesmo com deficiência de recursos financeiros, abrindo aos finais de semana.

\begin{abstract}
Segundo a estrutura básica, é herança de um antigo hospital de tuberculosos, é um prédio bem amplo com várias salas de atendimentos, identificadas por cores, (sala verde, sala amarela, dentre outras). Existe duas salas grandes sendo que uma é destinada a realização de oficinas e outra para grupos e reunião de equipe. No andar inferior há uma horta, um lugar onde estão organizando um jardim, uma espécie de quadra de futebol, uns banquinhos para os pacientes tomarem sol, e também uma ampla sala onde ocorrem oficinas de alfabetização. [ $\left.\begin{array}{ll}0 & 1\end{array}\right]$
\end{abstract}

A reunião do CAPS com a coordenação municipal de saúde mental ocorre uma vez por semana, onde são abordados assuntos referentes a toda rede do serviço de saúde mental. Há, também reuniões de equipe semanais, com a participação de todos os profissionais, de todos os níveis de conhecimento (sejam técnicos de nível superior ou não). Neste espaço são tratados assuntos inerentes aos usuários, há um repasse de informações percebidas nas visitas domiciliares, questões administrativas, preocupação com a educação permanente da equipe, com a inserção social do indivíduo, a organização das atividades internas do serviço, oficinas, articulação com outros segmentos sociais como a promotoria pública.

A equipe profissional é composta por dois médicos sendo um psiquiatra e outro clínico, duas enfermeiras, quatro técnicos de enfermagem, um acompanhante terapêutico, um assistente social, seis psicólogos, um terapeuta ocupacional, sete oficineiros (seis são estagiários pela Prefeitura Municipal, com contratos de duração de dois anos) que possuem formação em educação física e pedagogia; possui ainda, três profissionais na recepção, uma cozinheira, três funcionários na higienização, um motorista e quatro parceiros voluntários (sendo que um deles é nutricionista).

\title{
A política de saúde mental no município de Alegrete
}

No marcador das políticas de saúde mental entendida a partir do contexto geral das políticas públicas e de um contexto específico do município centramos a avaliação qualitativa na relação entre a Secretaria Municipal de Saúde e o CAPS, e na relação entre os princípios e a trajetória da luta antimanicomial no estado do Rio Grande do Sul e a construção da saúde mental em Alegrete, tendo como serviço estratégico o CAPS. 
No que se refere à relação entre o CAPS e a Secretaria Municipal de Saúde a equipe percebe o Secretário distanciado do CAPS o que acaba interferindo nas metas almejadas pela equipe.

\begin{abstract}
Não tenho muita ligação, não vejo isso acontecer, porque trabalho só com as oficinas [...] Eu não vejo nenhuma participação da Secretaria de Saúde Municipal, inclusive não conheço o Secretário. Então, acho que nós teríamos que agendar para conhecê-lo, eu acho engraçado isso aí. [E 17]

É uma gestão conservadora que não conseguiu entender porque a gente faz e o que faz aqui. Sempre entendeu isso como um processo de politização partidária e não é. Isso é uma construção política de saúde, que entende que saúde e atenção não se divorciam de gestão [...] Então os gestores eles foram parceiros, mas uma parceria meio que sucumbida pelo processo do movimento. Quem é ator de saúde mental nesse município é esse modelo que articula um pouco com o gestor, que articula um pouco com a Câmara, que articula um pouco com executivo. Esse movimento tem sido o gestor do espaço. E é quem dá suporte e, briga com quem tem que brigar. [E 6]
\end{abstract}

Alguns familiares referem que está tudo muito bom, outros consideram que a gestão municipal não está ajudando como seria o esperado. Consideramos que o fato do familiar estar mais engajado na dinâmica do serviço, participando mais ou menos intensamente do seu cotidiano influencia a percepção que o mesmo tem acerca da gestão.

Reconhece o trabalho, mas falta mais investimento da gestão. Eles estão ajudando. Eles têm que colocar mais gente, porque os profissionais podem sair e não ter outros. [F 2]

Eu acho, porque todas as coisas que tem ali é a Prefeitura que nos ajuda [...] O pão assim, se não é a Prefeitura, da onde que eles vão tirar [...] Muitas coisas a Prefeitura também deu e também ajuda. [F 4]

A Prefeitura, nessa época, ela está ajudando, mas quando eu comecei lá não estava ajudando, estava tudo muito lá embaixo. [F 12 ]

O posicionamento do usuário sobre a relação do serviço com a Secretaria Municipal de Saúde também é bastante explícito sobre as contribuições e limites. A burocracia, a dificuldade de compreender e acolher as necessidades imediatas e de expansão da saúde mental são destacadas. A relação é marcada por um processo contínuo de luta, que atravessa as diferentes administrações dos diferentes 
partidos ou que é marcada por oscilações na relação no interior da mesma gestão.

As experiências de Santos e Campinas, no estado de São Paulo, são consideradas fundantes no processo de transição paradigmática entre o modo manicomial e o modo psicossocial. Evidencia-se que a descontinuidade político-administrativa trouxe efeitos negativos em ambas, no entanto nos mostra que com o compromisso político dos gestores, a implicação das equipes dos serviços e a organização dos usuários, é possível construir-se historicamente a mudança do modelo de atenção em saúde mental (LUZIO; L'ABBATE, 2006).

Constata-se no caso de Alegrete que o processo de mudança é construído pelos "sujeitos da saúde mental" (trabalhadores, usuários e familiares) que vão gerando demandas, tensionando em cima das necessidades e acumulando conquistas. $O$ movimento de sensibilização da gestão para as necessidades da saúde mental tem sido contínuo na história da saúde mental de Alegrete.

Acho que eles têm uma barreira [...] tem uma barreira, porque ... Não sei se é a cabeça das pessoas. A coisa se expandiu, a saúde mental se expandiu. Tinha uma sala no pronto-atendimento, aí conseguiram uma casinha num conjunto habitacional [...] Uma casinha, daí vieram para cá, e tudo com muita luta, de meia dúzia de profissionais da área [...] E está isso aqui, lindo, esse prédio todo reformado, um atendimento maravilhoso [...] Mas tem essa barreira. [U 7]

Eles não tem investido muito no serviço de saúde mental. Todas as coisas que nós conseguimos foi brigando. [U 11]

Da coordenação de saúde mental que lutou para mudar esse negócio. Porque as pessoas vinham para cá eram três da manhã, às vezes ficavam das dez da manhã até às sete da manhã do outro dia para esperar para marcar uma ficha [...] Falta de interesse deles [...] De investimento e de apoiar o serviço, de ajudar. Para conseguir qualquer coisa é uma burocracia, tem que virar o mundo para conseguir qualquer coisa. [U 1]

A noção de sujeito social desenvolvida por Sader (1988) permite-nos identificar no processo constituído em Alegrete um movimento de saúde mental, em que os diferentes indivíduos que o integram constituem-se como sujeitos sociais e em que o próprio movimento da saúde mental constrói-se como um sujeito coletivo.

Sader (1988), ao discutir as novas configurações assumidas pelos trabalhadores e movimentos sociais da Grande São Paulo na década de 70, apresenta uma definição de sujeito social que compartilhamos. Na sua pesquisa, associa a noção de sujeito à existência de um projeto e à idéia de autonomia. Afirma que, um traço comum no emprego do conceito de sujeito encontrado no interior dos novos 
movimentos sociais é:

O fato de a noção de sujeito vir associada a um projeto, a partir de uma realidade cujos contornos não estão plenamente dados e em cujo devir o próprio analista projeta suas perspectivas e faz suas apostas. E outro traço comum, vinculado a este, é a conotação com a idéia de autonomia, como elaboração da própria identidade e de projetos coletivos de mudança social a partir das próprias experiências [...] Quando uso a noção de sujeito coletivo é no sentido de uma coletividade onde se elabora uma identidade e se organizam práticas através das quais seus membros pretendem defender seus interesses e expressar suas vontades, constituindo-se nestas lutas. (SADER, 1988, p. 53-55).

Quando o usuário 1 e o usuário 7 mencionam que “[...] saúde mental se expandiu e que tem que virar o mundo para conseguir alguma coisa" reafirma-se neste caso em particular de Alegrete-RS que o movimento antimanicomial constitui-se em espaço de empoderamento dos sujeitos sociais conforme afirmam Lückmann e Rodrigues (2007), Kantorski e Silva (2001).

Para Kantorski e Silva (2001) o movimento pela reforma psiquiátrica constitui-se em um sujeito coletivo no interior da sociedade civil, que resiste a ideologia dominante do manicômio, na luta para ganhar espaço, produzir novos valores, construir novos sujeitos sociais. Concebendo sujeitos sociais como atores emergentes que se aglutinam em torno de um projeto social e político de reforma psiquiátrica que visa a transformar a ordem manicomial hegemônica, contrapor-se e resistir a ela.

Segundo Castoriadis (1991), o sujeito social não é nem um sujeito enquanto atividade-pura, livre de determinações externas, mas é aquele capaz de reelaborar o discurso do Outro em função de suas vontades. O sujeito autônomo é também atividade, intencionalidade, é também o corpo no mundo, antes de qualquer pensamento que possa ser refletido.

Tais concepções sugerem que a autonomia está no centro dos objetivos do projeto de transformação e, portanto tem de ser pensada para todos os homens, sua concretização requerendo um trabalho coletivo.

\section{Considerações Finais}

Estabelecer marcadores para avaliar qualitativamente um serviço de saúde mental, como o CAPS, que é estratégico na mudança do modelo de atenção em saúde mental no interior das políticas públicas no Brasil consiste num desafio de grande porte.

Para tanto decidimos assumi-lo tendo como suporte uma metodologia de avaliação qualitativa construtivista, formativa e responsiva, a qual 
chama para a cena da avaliação além dos pesquisadores outros atores como trabalhadores de saúde, usuários do serviço de saúde mental e seus familiares.

Neste sentido a opção metodológica favoreceu a apreensão da riqueza subjetiva dos sentidos conferida a trajetória e a relação estabelecida pelos diferentes protagonistas com a Secretaria Municipal de Saúde e a luta antimanicomial.

\section{Referências Bibliográficas}

ALVERGA, A. R.; DIMENSTEIN, M. A reforma psiquiátrica e os desafios na desinstitucionalização da loucura. Interface comunicação, saúde, educação, Botucatu, v.10, n.20, p.299-316, jul. 2006.

ARENDT, H. Homens em tempos sombrios. São Paulo: Companhia das Letras, 1987.

BEZERRA JÚNIOR, B. De médico, de louco e de todo mundo um pouco: o campo psiquiátrico no Brasil dos anos 80. In: GUIMARÃES, R.; TAVARES, R. A. W. (Orgs.). Saúde e sociedade no Brasil: anos 80. Rio de Janeiro: Relume-Dumará, 1994, p.171-191.

BRASIL. Instituto Brasileiro de Geografia e Estatística - IBGE. Disponível em: http://www.ibge.gov.br/cidadesat/topwindow. htm?1 Acesso em: 10 jan. 2007.

CAMPOS, G. W. S. Modelos de atenção em saúde pública: um modo mutante de fazer saúde. Saúde em Debate, Rio de Janeiro, v.40, n. 37, p. 16-19, dez. 1992.

CASTORIADIS, C. A instituição imaginária da sociedade. Rio de J aneiro: Paz e Terra, 1991.

DONABEDIAN, A. La calidad de la atención medica: definición y metodos de evaluación. Ciudad de Mexico: Ediciones cientificas la prensa medica mexicana, S. A; Ediciones Copilco, S. A., 1984.

. The quality of care - How can it be assessed? J ournal of the

American Medical Association, Washington, v. 12, n. 260, p. 1743-1748, 1988.

FERNANDES A. B. Jornalismo e cidadania, configurações da luta por direitos legais dos doentes mentais nos espaços públicos. In: CONGRESSO BRASILEIRO DE CIÊNCIAS DA COMUNICAÇÃO, 24. 2001, São Paulo. Anais... São Paulo: Intercom/Portcom, 2001. Disponível em: http://reposcom.portcom.intercom.org.br/bitstream L1904/4359/1/NP2FERNANDES.pdf Acesso em: dez. 2006.

GUBA, E; LINCOLN, Y. Effective evaluation: improving the usefulness of evaluation results throug responsive naturalistic approaches. San Francisco: J ossey-Bass Pub. 1985.

Fourth generation evaluation. Newbury Park: Sage Pübüications, 1989. 
$\overline{1} \overline{9} \overline{9} \overline{8}$.

Effective evalution. San Francisco: Jossey Bass Publishers,

KANTORSKI, L. P.; SILVA, G. B. A Reforma psiquiátrica em questão. In: $\quad$. (Orgs.). Ensino de enfermagem e reforma psiquiátríca. Pelotas: Editora UFPel, 2001, p. $141-210$.

LANCETTI, A. Saúde mental nas entranhas da metrópole. In: JANETE, A.; LANCETTI, A. (Orgs.). Saúde mental e saúde da família. 2.ed. São Paulo: Hucitec, 2001, p. 11- 52.

LÜCHMANN, L. H. H.; RODRIGUES, J. O movimento antimanicomial no Brasil. Ciência e saúde coletiva, Rio de Janeiro, v. 12, n.2, p.399-407, jul. 2007.

LÜDKE, M.; ANDRÉ, M.E.D.A. Pesquisa em educação: abordagens qualitativas. São Paulo: EPU, 1986.

LUZIO, C. A.; L'ABBATE, S. A reforma psiquiátrica brasileira: aspectos históricos e técnico-assistenciais das experiências de São Paulo, Santos e Campinas. Interface - Comunicação, saúde, educação, Botucatu, v.10, n.20, p.281-98, jul. 2006.

OLIVEIRA, D. C.; SALDANHA, O. L. Da instituição à sociedade: a trajetória da saúde mental coletiva. Revista Saúde Mental Coletiva, Bagé, v.1, p 40-50, jun. 1993.

PATTON, M. Q. How to use qualitative methods in evaluation. Newbury Park: Sage Publications, 1987.

SADER, E. Quando novos personagens entram em cena: experiências e lutas dos trabalhadores da Grande São Paulo 19701980. Rio de Janeiro: Paz e Terra, 1988.

SAÚDE MENTAL COLETIVA. Fóruns. Revista de Divulgação do Fórum Gaúcho de Saúde Mental, Bagé, v. 1, p.82-83, jun. 1993.

SILVEIRA, D.P.; VIEIRA, A.L.S.V. Reflexões sobre a ética do cuidado em saúde: desafios para a atenção psicossocial no Brasil. Estudos e Pesquisas em Psicologia UERJ, Rio de Janeiro, v. 5, n.1, p. 92101, 2005.

TESTA, M. Pensar em saúde. Porto Alegre: Artes Médicas, 1992.

WETZEL, C. Avaliação de serviços de saúde mental: a construção de um processo participativo. 2005. 290f. Tese (Doutorado em Enfermagem). Escola de Enfermagem de Ribeirão Preto, Universidade de São Paulo, Ribeirão Preto.

YIN, R. K. Estudo de caso: planejamento e métodos. 3. ed. Porto Alegre: Bookman, 2005.

\section{Endereço para correspondência}

Luciane Prado Kantorski

Universidade Federal de Pelotas, Rua XV de Novembro 209, CEP 96020-250, Pelotas - RS, Brasil

Endereço eletrônico: kantorski@uol.com.br

Vanda Maria da Rosa Jardim

Faculdade de Enfermagem e Obstetrícia da Universidade Federal de Pelotas, Rua XV de novembro 209, CEP 96020-250, Pelotas - RS, Brasil 
Endereço eletrônico: phein@uol.com.br

Valéria Cristina Christello Coimbra

Faculdade de Enfermagem e Obstetrícia da Universidade Federal de Pelotas, Rua XV de novembro 209, CEP 96020-250, Pelotas - RS, Brasil

Endereço eletrônico: valeriacoimbra@hotmail.com

Álvaro Moreira Hypólito

Faculdade de Educação da Universidade Federal de Pelotas, Rua XV de novembro 209, CEP 96020-250, Pelotas - RS, Brasil

Endereço eletrônico: alvaro.hypolito@gmail.com

Ariane da Cruz Guedes

Programa de Pós-Graduação em Enfermagem da Universidade Federal de Pelotas Universidade Federal de Pelotas, Rua XV de novembro 209, CEP 96020-250, Pelotas - RS, Brasil

Endereço eletrônico: ariane.guedes@yahoo.com.br

Maria Carolina Meirelles

Programa de Pós-Graduação em Enfermagem da Universidade Federal de Pelotas,

Rua XV de novembro 209, CEP 96020-250, Pelotas - RS, Brasil

Endereço eletrônico: carolinapmeirelles@yahoo.com.br

Bianca Neme Clasen

Programa de Pós-Graduação em Enfermagem da Universidade Federal de Pelotas, Rua XV de novembro 209, CEP 96020-250, Pelotas - RS, Brasil

Endereço eletrônico: biancaneme@hotmail.com

Cláudio Tosi Cavada

Programa de Pós-Graduação em Enfermagem da Universidade Federal de Pelotas,

Rua XV de novembro 209, CEP 96020-250, Pelotas - RS, Brasil

Endereço eletrônico: claudio.cavada@hotmail.com

J andro Moraes Cortes

Faculdade de Enfermagem da Universidade Federal de Pelotas, Rua XV de novembro 209, CEP 96020-250, Pelotas - RS, Brasil

Endereço eletrônico: jandromcortes@hotmail.com

Recebido em: 31/07/2009

Aceito para publicação em: 12/11/2009

Acompanhamento do processo editorial: Deise Mancebo, Marisa Lopes da Rocha e Roberta Carvalho Romagnoli

\section{Nota}

* Enfermeira; Doutora em Enfermagem

** Enfermeira; Doutora em Enfermagem

*** Enfermeira; Doutora em Enfermagem Psiquiátrica

$* * * *$ Pedagogo, PhD em Curriculum and Instruction

***** Enfermeira; mestranda do Programa de Pós-Graduação em Enfermagem da

Universidade Federal de Pelotas, Bolsista de Apoio Técnico à Pesquisa - CNPq

****** Enfermeira; mestranda do Programa de Pós-Graduação em Enfermagem da Universidade Federal de Pelotas

******* Enfermeira; mestranda do Programa de Pós-Graduação em Enfermagem da Universidade Federal de Pelotas

******** Enfermeiro; mestrando do Programa de Pós-Graduação em Enfermagem da Universidade Federal de Pelotas

********* Acadêmico do 9o semestre do curso de Enfermagem e Obstetrícia da Universidade Federal de Pelotas; Monitor de Enfermagem Psiquiátrica e Saúde Mental na mesma Universidade 
1 Pesquisa financiada pelo Conselho Nacional de Desenvolvimento Científico e Tecnológico (MCT-CNPq / MS-SCTIE-DECIT-CT-Saúde - Edital 07/200 № PROCESSO: 554537/2005-2) 